\title{
A web-based appointment system to reduce waiting for outpatients: A retrospective study
}

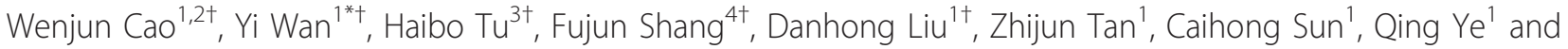 \\ Yongyong $\mathrm{Xu}^{1 *}$
}

\begin{abstract}
Background: Long waiting times for registration to see a doctor is problematic in China, especially in tertiary hospitals. To address this issue, a web-based appointment system was developed for the Xijing hospital. The aim of this study was to investigate the efficacy of the web-based appointment system in the registration service for outpatients.

Methods: Data from the web-based appointment system in Xijing hospital from January to December 2010 were collected using a stratified random sampling method, from which participants were randomly selected for a telephone interview asking for detailed information on using the system. Patients who registered through registration windows were randomly selected as a comparison group, and completed a questionnaire on-site.

Results: A total of 5641 patients using the online booking service were available for data analysis. Of them, 500 were randomly selected, and 369 (73.8\%) completed a telephone interview. Of the 500 patients using the usual queuing method who were randomly selected for inclusion in the study, responses were obtained from 463, a response rate of $92.6 \%$. Between the two registration methods, there were significant differences in age, degree of satisfaction, and total waiting time $(P<0.001)$. However, gender, urban residence, and valid waiting time showed no significant differences $(P>0.05)$. Being ignorant of online registration, not trusting the internet, and a lack of ability to use a computer were three main reasons given for not using the web-based appointment system. The overall proportion of non-attendance was $14.4 \%$ for those using the web-based appointment system, and the nonattendance rate was significantly different among different hospital departments, day of the week, and time of the day $(P<0.001)$.
\end{abstract}

Conclusion: Compared to the usual queuing method, the web-based appointment system could significantly increase patient's satisfaction with registration and reduce total waiting time effectively. However, further improvements are needed for broad use of the system.

Keywords: Web-based appointment system, registration, waiting time, patient satisfaction, non-attendance

\section{Background}

Reducing outpatient waiting times has been the focus of a large number of studies [1-3] because waiting and treatment times are usually regarded as indicators of service quality [4]. The Patient's Charter of the UK Government sets a series of standards which state that all patients must be seen within thirty minutes of their

\footnotetext{
* Correspondence: wanyi@fmmu.edu.cn; xuyongy@fmmu.edu.cn

† Contributed equally

'Department of Health Statistics, School of Preventive Medicine, Fourth Military Medical University, Xi'an 710032, China

Full list of author information is available at the end of the article
}

appointment time [1]. Outpatient waiting time can be divided into two types: waiting before consultation, and waiting after consultation [5]. Time spent waiting before consultation has attracted much research attention, and can be further separated into waiting time for registration, and waiting time for consultation [6]. Because of China's limited medical resources, long waiting times for registration are common in the health care system, and the registration waiting time is generally much longer than the consultation waiting time. Long registration waiting times for outpatients have already become a long-festering healthcare problem in China [7]. For this

\section{() Biomed Central}


reason, our study focuses on registration waiting time only.

In recent years, China has been in the process of implementing health care system reform [8]. The aim of the reform was to provide basic and convenient medical care. Easy access to a doctor is the first step for patients using health services. The traditional registration method (usual queuing method), had unacceptable waiting times, and placed great stress on clinic staff [7]. With the rapid development of the internet over the previous 2-3 years, some hospitals trialed the use of web-based appointment systems (WAS) for outpatients [9]. In 2009, supported by the Ministry of Health, all public tertiary hospitals began to use WAS. However, to date there are few studies about the efficacy of WAS in China. Thus, our study aims to evaluate the efficacy of WAS for outpatients, by comparing waiting times for the WAS and usual queue method, and investigating reasons for not using the WAS.

\section{Methods}

\section{Study Participants}

This work was approved by the ethics committee of Xijing hospital, Fourth Military Medical University. Informed consent was obtained from participants prior to the administration of study measures.

Study participants were recruited from outpatients of Xijing hospital, which is a tertiary hospital in Shaanxi province of China. A two-stage sampling method was adopted. First, from January to December 2010, 10\% of all patients registering through the WAS were randomly selected for potential inclusion in the study, giving a total of 5641 patients. For each patient, detailed information including demographic characteristics, appointment, and contact data were obtained from the hospital statistics office. Then, from the selected patients, 500 were randomly selected for a telephone interview. The interview assessed satisfaction with the WAS and the time spent making appointments, and were performed by trained interviewers.

The comparison group completed a questionnaire and comprised 500 randomly selected patients who used the usual queuing method for registration. Interviewers distributed questionnaires to people queuing at registration windows, and supervisors were responsible for the collection of completed questionnaires after registration. The following questions were listed in the questionnaires:

1. What time did you join the queue?

2. What is your reason for not using the web-based registration system?

3. Are you satisfied with the usual queuing method?

4. What time did you register successfully?

The last question was confirmed by the registering nurses.

\section{Main outcome measures}

We evaluated the performance of two different approaches: the WAS, and the usual queuing method (Figure 1). Using the WAS, patients are given an appointment number. At the designated appointment time, patients arrive at the hospital and get the registration that is allotted to their appointment number. These patients need not queue at the registration window. The patients using the traditional queuing method waste much unnecessary waiting time standing in line at the registration window to ensure a successful registration with a certain physician. The main outcome variables were: invalid, valid, and total waiting time based on the usual queuing method, and appointment-making time based on the WAS. "Invalid waiting time" was defined as the duration of time spent queuing for registration; and "total waiting time" was the total time spent queuing and obtaining registration, and consists of valid and invalid waiting time. Appointment-making time based on the WAS was the duration of time the participant spent making an appointment through the WAS.

\section{Statistical Analysis}

We used SPSS 17.0 for Windows (SPSS Inc, Chicago, Illinois) for all statistical analysis. Continuous variables are presented as means and standard deviations. Categorical variables are presented as frequencies and percentages. The $t$-test, analysis of variance (ANOVA), MannWhitney $U$ test, and Kruskal-Wallis $H$ test were used to

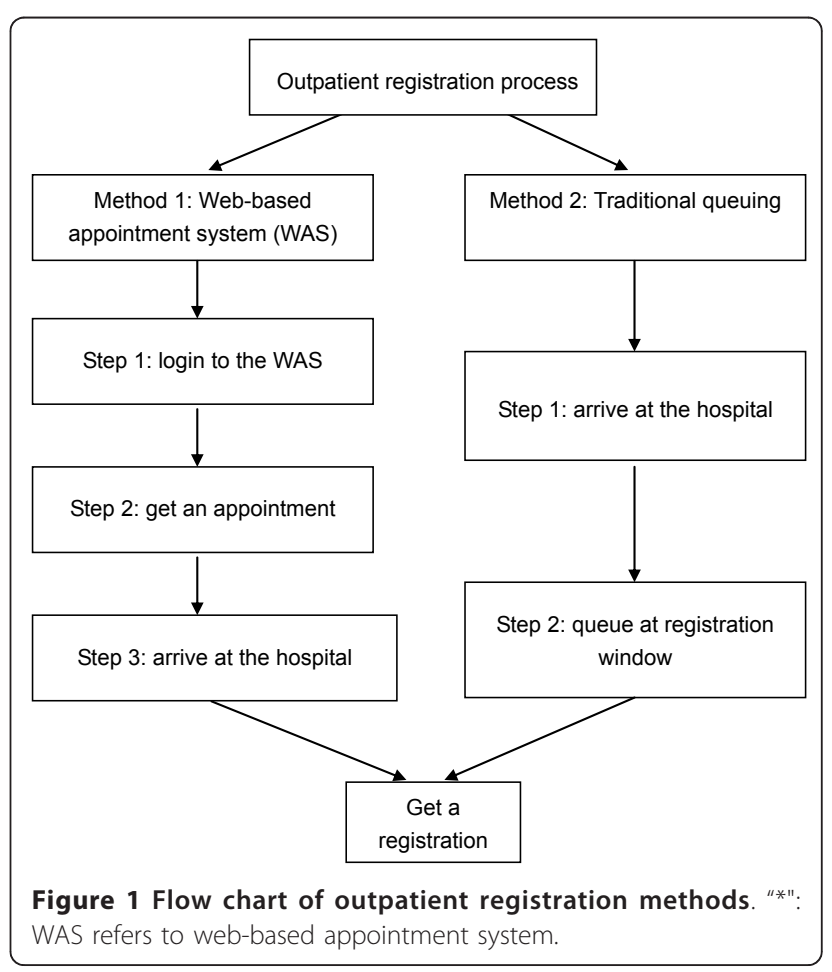


compare continuous variables, and the Chi-square test was used to compare categorical variables between the two registration systems. A two-tailed $P$-value $<0.05$ was considered statistically significant.

\section{Results}

A total of 5641 people made an appointment using the WAS in the study period, from which 500 were randomly selected for a telephone interview. Responses were obtained from 369 (73.8\%) participants. For the usual queuing method group, 463 participants completed a questionnaire while queuing for registration, corresponding to a response rate of $92.6 \%(463 / 500)$.

\section{The demographic characteristics of participants}

Participant gender and residence distributions did not differ between the two registration methods $(P>$ $0.05)$. However, the age distribution was significantly different between the two methods, with the average age of participants being younger in the WAS group (Table 1).

\section{Satisfaction and waiting time comparison between the two registration methods}

Participants using the WAS reported a higher level of satisfaction with the registration method than those using the usual queuing method $(71.7 \%$ vs. $49.0 \%, P<$ $0.001)$. In the usual queuing method, the average invalid waiting time was 86 minutes with a maximum of 13.5 hours; while the average valid waiting time was only 12 minutes (Figure 2). Although the total waiting time of the usual queuing method was significantly longer than that of the WAS method (98 vs. 7 minutes, $P<0.001$ ) (Table 1 ), there were no significant differences in valid waiting time between the usual queuing method and the WAS method (12 vs. 7 minutes, $P=$ $0.321)$.

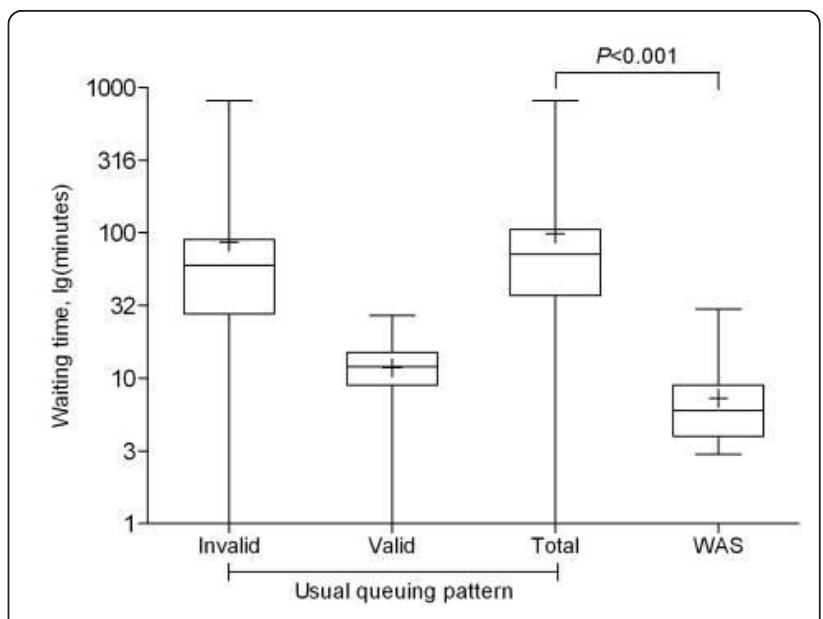

Figure 2 Box-plot of waiting time for usual queuing vs. WAS "+": mean values; "WAS": web-based appointment system.

\section{Reasons for not using the WAS}

The most common reason given by participants for not using the WAS was that they were unaware of its existence $(52.9 \%)$ (Table 2). Other factors leading to the non-use of the WAS were that people did not trust the internet $(28.1 \%)$, and/or lacked the ability to operate a computer $(10.4 \%)$. Only $8.6 \%$ of participants had other reasons, such as that it was casual decision to see a doctor, or that certain physicians had no extra "passports" to be booked.

\section{Non-attendance following use of the WAS}

The overall proportion of non-attendance following making an appointment using the WAS was $14.4 \%$. Non-attendance rates differed among the 30 hospital departments (Kruskal-Wallis $H$ test, $\chi^{2}=32.128, P<$ 0.001 ), and varied between $0.16 \%$ and $15.7 \%$. Neurosurgery, General surgery, Urology, Obstetrics and Gynecology, and Ophthalmology had the highest rates of nonattendance (Table 3). Non-attendance was higher on

Table 1 Demographic factors, degree of satisfaction, and waiting time for participants using usual queuing vs. webbased appointment system

\begin{tabular}{|c|c|c|c|}
\hline Variable & Usual queue method $(n=463)$ & Web-based appointment system $(n=369)$ & $P$ value \\
\hline Age, $y$, mean $\pm S D$ & $46 \pm 10$ & $34 \pm 8$ & $<0.001$ \\
\hline$\leq 30(\%)$ & $15(3.2)$ & $105(28.5)$ & $<0.001$ \\
\hline 30-39 (\%) & $85(18.4)$ & $183(49.6)$ & - \\
\hline $40-49(\%)$ & $219(47.3)$ & $54(14.6)$ & - \\
\hline$\geq 50(\%)$ & $144(31.1)$ & $27(7.3)$ & - \\
\hline Gender, n (\%) & & & 0.337 \\
\hline Male & $162(35.0)$ & $141(38.2)$ & - \\
\hline Female & $301(65.0)$ & $228(61.8)$ & - \\
\hline Urban residence, $n$ (\% in Xi'an zip code) & $271(58.5)$ & $239(64.8)$ & 0.066 \\
\hline Satisfaction, n (\%) & $332(71.7)$ & $181(49.0)$ & $<0.001$ \\
\hline Average total waiting time, minutes, median (range) & $98(1-811)$ & 7 (3-27) & $<0.001$ \\
\hline
\end{tabular}


Table 2 Participant reasons for not using the WAS

\begin{tabular}{ll}
\hline Reasons & Participants, $\boldsymbol{n}$ (\%) \\
\hline Unaware of the online appointment service & $245 / 463(52.9)$ \\
Did not trust the internet & $130 / 463(28.1)$ \\
No computer literacy & $48 / 463(10.4)$ \\
Others & $40 / 463(8.6)$ \\
\hline
\end{tabular}

Mondays than on any other day $(P<0.001)$. During daytime, the non-attendance rate between $1 \mathrm{pm}$ and 4 pm was higher than the rate between 8 am and $11 \mathrm{am}$ (24.6\% vs. $10.7 \%, P<0.001$ ) (Table 3 ).

\section{Discussion}

One of the greatest complaints of the Chinese public is the amount of time it takes to queue for outpatient registration in China. From our investigation we noted that some participants even waited in line all night (13.5 hours) to ensure a registration with a certain physician. To effectively reduce registration waiting times in the usual queuing method is an urgent issue that needs to be resolved. This study demonstrates that that using a WAS could substantially increase patients' satisfaction with outpatient registration. Although some time is still needed to make appointments using the WAS, it can significantly reduce total waiting time, especially invalid waiting time.

Despite the benefits using of the WAS, many people still registered via the usual queuing method. One reason we identified for not using the WAS was that over

Table 3 Non-attendance rates in different subgroups of participants using the WAS ( $n=5641$ )

\begin{tabular}{llc}
\hline Variable & Non-attendance, no. (\%) & $P$ value \\
\hline Overall & $812 / 5641(14.4)$ & - \\
Department & & $<0.001$ \\
$\quad$ Neurosurgery & $144 / 829(28.6)$ & - \\
$\quad$ General surgery & $14 / 69(28.1)$ & - \\
$\quad$ Urology & $20 / 112(17.9)$ & - \\
$\quad$ Obstetrics and Gynecology & $140 / 787(17.8)$ & - \\
$\quad$ Ophthalmology & $73 / 416(17.5)$ & - \\
Other & $421 / 3428(12.3)$ & - \\
Day of the week & & $<0.001$ \\
Sunday & $6 / 51(0.9)$ & - \\
Monday & $224 / 1230(18.2)$ & - \\
Tuesday & $160 / 1241(12.9)$ & - \\
Wednesday & $146 / 919(15.9)$ & - \\
Thursday & $126 / 965(13.1)$ & - \\
Friday & $125 / 970(12.9)$ & - \\
Saturday & $25 / 265(9.6)$ & - \\
Hours of the day & & - \\
08:00 to 11:00 & $442 / 4138(10.7)$ & \\
13:00 to 16:00 & $370 / 1503(24.6)$ & \\
\hline
\end{tabular}

half of the participants did not know that an appointment can be obtained through the internet. This indicates that more effort should be made by hospitals and health service providers to promote and encourage the use of the WAS. By using a WAS, hospitals and other health service providers can reduce their invalid waiting time and anxiety in queues. Another important finding was that registration demand varied according to day of the week and time of the day. After investigating patient's appointment time in the WAS, we found that $43.8 \%$ of patients (2471) wanted to see a doctor on Monday or Tuesday, and $71.0 \%$ of them preferred it to be in the morning. This makes it very difficult to obtain registration during these periods. By making patients aware of this, it would be possible to encourage them to register on days with a lower outpatient load. This will help distribute the registration demand evenly and improve the allocation of medical resources.

Non-attendance is one of the potential problems for hospitals using a WAS. In our study, the overall nonattendance rate was $14.4 \%$. This is consistent with the non-attendance rates reported in related studies, which range from $12 \%$ to $27 \%[10,11]$. We found that the proportion of non-attendance was higher on Mondays than on other days, which differs from another study, which reported that non-attendance rates were higher on Sundays than on other days [12]. The failure of patients to meet scheduled appointments disrupts the orderliness of medical care and wastes limited medical resources $[12,13]$. Some measures had already been adopted to address this issue, such as preventing patients who failed to attend appointments three times in the preceding 12 months from making any new appointments on the web.

Many studies have focused on reasons for non-attendance, and some reliable suggestions for improvement have been provided (e.g., using a reminder system) [14-16]. To improve the management of outpatients, we assessed non-attendance related factors in our study. We found that hospital department, day of the week, and time of the day were significantly associated with non-attendance. The proportion of non-attendance was higher following registration with medical specialists (e. g. specialists in Neurosurgery) and most non-attendance occurred in the afternoon.

Our study has some potential limitations. First, we failed to collect data on the reasons for non-attendance from the participants using the WAS, because the majority of people who failed to attend their appointments declined to give an explanation. Second, because our study participants were from a large tertiary hospital, and different hospitals may have a different WAS, our findings may not reflect WAS use in other hospitals. Some relatively small hospitals may not need to use a 
WAS, because they do not experience high demand for registration. Despite these potential limitations, our study demonstrated that the WAS is an efficient and satisfactory means of obtaining registration, and identified factors that contribute to not using the booking system. By identifying these factors, we intend to develop intervention strategies to further improve the usability of the WAS and provide convenience for patients.

\section{Conclusion}

Our study showed that use of a WAS can effectively increase patient satisfaction with getting a registration and reduce waiting times. A lack of information about online appointments was the main reason for not using the system. Non-attendance is an inevitable problem in the development of a web-based registration system. To increase the efficiency of the registration system, and to reduce non-attendance rates, further studies on various interventions such as the promotion of online registration, and use of a reminder system should be considered.

\section{Acknowledgements}

Dr. YW was supported by the research program of Fourth Military Medical University. Prof. YX was supported by the National Science and Technology Support Project Grant (No. 2008BAl52B01) from the Ministry of Science and Technology and National Natural Science Foundation (No. 81072393) of China.

\section{Author details}

'Department of Health Statistics, School of Preventive Medicine, Fourth Military Medical University, Xi'an 710032, China. ${ }^{2}$ Department of Mathematics, Chang Zhi Medical College, Changzhi, Shanxi Province 046000, China. ${ }^{3}$ Division of Medical Service, Xijing Hospital, Fourth Military Medical University, Xi'an 710032, China. ${ }^{4}$ Tangdu Hospital, Fourth Military Medical University, Xi'an 710038, China.

\section{Authors' contributions}

The initial idea was supplied by YW and YX. The protocol was drawn by YW and WC. Investigation was carried by DL, WC, HT, FS, ZT, CS and QY. Data extraction and analyses were performed by WC and YW. First draft was written by WC with contributions by YW. All authors commented and approved the final draft.

\section{Conflicts of interests}

The authors declare that they have no competing interests.

Received: 27 May 2011 Accepted: 22 November 2011 Published: 22 November 2011

\section{References}

1. Harper PR, Gamlin HM: Reduced outpatient waiting times with improved appointment scheduling: a simulation modeling approach. OR Spectrum 2003, 25:207-222.

2. Zhu ZC, Heng BH, Teow KL: Analysis of factors causing long patient waiting time and clinic overtime in outpatient clinics. J Med Syst 2010.

3. Najmuddin AF, Ibrahim IM, Ismail SR: Simulation modeling and analysis of multiphase patient flow in obstetrics and gynecology department (O\&G Department) in specialist centre. ASM'10 Proceedings of the 4 th international conference on Applied mathematics, simulation, modeling 2010, 125-130.
4. Wijewickrama AK, Takakuwa S: Simulation analysis of an outpatient department of internal medicine in a university hospital. Proceedings of the 2006 Winter Simulation Conference 2006, 425-432.

5. Chen BL, Li ED, Yamawuchi K, Kato K, Naganawa S, Miao WJ: Impact of adjustment measures on reducing outpatient waiting time in a community hospital: application of a computer simulation. Chin Med J 2010, 123:574-580

6. $Y u$ Q, Yang K: Hospital registration waiting time reduction through process redesign. International Journal of Six Sigma and Competitive Advantage 2008, 4:240-253.

7. Private hospitals shoulder hopes of revamping China's ailing medical system. [http://english.peopledaily.com.cn/90001/90776/90882/6916485. html].

8. Ma J, Lu MS, Quan H: From a national, centrally planned health system to a system based on the Market: Lessons from China. Health Aff 2008, 27:937-948.

9. Wei XF, Huang YS: Modeling outpatient booking system based on UML [in Chinese]. Science Technology and Engineering 2007, 7:5600-5603.

10. Adams LA, Pawlik J, Forbes GM: Non-attendance at outpatient endoscopy. Endoscopy 2004, 36:402-404.

11. Raju G, Boening SK, Mielsch EJ, Jafri SF, Bhutani MS, Szauter K, Shabot JM, Synder N III, Nath SK, Faruqi S, Pasricha PJ: Patient compliance is key to the success of an open-access colonoscopy program. Gastrointest Endosc 2003, 57:AB112.

12. Goldbart AD, Dreiher J, Vardy DA, Alkrinawi S, Cohen AD: Non-attendance in pediatric pulmonary clinics: an ambulatory survey. BMC Pulm Med 2009, 9:12.

13. Lee CS, McCormick PA: Telephone reminders to reduce non-attendance rate for endoscopy. J $R$ Soc Med 2003, 96:547-548.

14. Gurudu SR, Fry LC, Fleischer DE, Jones BH, Trunkenbolz MR, Leighton JA: Factors contributing to patient non-attendance at open-access endoscopy. Dig Dis Sci 2006, 51:1942-1945.

15. Dickey W, Morrow Jl: Can outpatient non-attendance be predicted from the referral letter? An audit of default at neurology clinics. $J$ R Soc Med 1991, 84:662-663.

16. Downer SR, Meara JG, Da Costa AC: Use of SMS text messaging to improve outpatient attendance. Med J Aust 2005, 183:366-368.

\section{Pre-publication history}

The pre-publication history for this paper can be accessed here: http://www.biomedcentral.com/1472-6963/11/318/prepub

\section{doi:10.1186/1472-6963-11-318}

Cite this article as: Cao et al:: A web-based appointment system to reduce waiting for outpatients: A retrospective study. BMC Health Services Research 2011 11:318.

\section{Submit your next manuscript to BioMed Central and take full advantage of:}

- Convenient online submission

- Thorough peer review

- No space constraints or color figure charges

- Immediate publication on acceptance

- Inclusion in PubMed, CAS, Scopus and Google Scholar

- Research which is freely available for redistribution

Submit your manuscript at www.biomedcentral.com/submit 